\title{
Erratum to: Rheological Properties of Polypropylene Reinforced Asphalt Binder
}

\author{
Punya Murty Kathari ${ }^{1,2}$. \\ Amarendra Kumar Sandra ${ }^{3}$ G. Avinash ${ }^{1}$. \\ P. Sravana ${ }^{1}$
}

Published online: 2 May 2016

(C) Springer Science+Business Media New York 2016

\section{Erratum to: Transp. Infrastruct. Geotech. Doi 10.1007/s40515-016-0033-3}

Due to a production error the names of several authors were omitted from the original article. They are presented correctly here.

The online version of the original article can be found at http://dx.doi.org/10.1007/s40515-016-0033-3.

\section{Punya Murty Kathari \\ katharip@gmail.com}

1 Department of Civil Engineering, JNTU, Hyderabad, Hyderabad, India

2 Plot No. 78, Flat No. 102, Neem Tree Park Cute Apartments, Matrusrinagar, Miyapur, Hyderabad 500049 Telangana State, India

3 GMR Infrastructure Limited, Hyderabad, India 